\title{
TÁC ĐỘNG CỦA NHÂN TỐ QUY MÔ ĐẾN VIÊCC VẬN DỤNG KẾ TOÁN QUẢN TR! TRONG CÁC DOANH NGHIỆP NHỎ VÀ VỬ TẠI VIẸTT NAM
}

\author{
TRÀ̀N NGỌC HÙNG \\ Trường Đại học Công nghiệp thành phố Hồ Chí Minh; \\ tranngochung@iuh.edu.vn
}

Tóm tắt. Khi bắt đầu xu hướng hội nhập, các doanh nghiệp nhỏ và vừa (DNNVV) Việt Nam đứng trước những cơ hội và thách thức mới: hoặc là tự đào thải, hoặc là thay đổi để bắt kịp nhịp phát triển: thay đổi về cấu trúc doanh nghiệp (DN), thay đổi về chiến lược cũng như triết lý quản trị; điều này làm cho doanh nghiệp ngày càng thích ứng tốt hơn, đáp ứng được nhu cầu của khách hàng nhanh hơn thông qua các quyết định kịp thời (Langfield-Smith và ctg., 2009). Với quy mô sản xuất nhỏ và chưa quen vận dụng các công cụ quản trị như kế toán quản trị (KTQT) nên các DNNVV gặp nhiều bất lợi khi cạnh tranh với các công ty lớn, các tập đoàn toàn cầu. Dựa trên lý thuyết nền tảng về KTQT, bài báo sử dụng các phương pháp nghiên cứu như kiểm định chi bình phương, ứng dụng mô hình nhân tố khám phá với kết quả nghiên cứu chỉ ra rằng nhân tố quy mô doanh nghiệp có tác động đến tính khả thi của việc vận dụng KTQT trong các DNNVV Việt Nam, từ đó đề xuất xây dựng các mô hình vận dụng KTQT phù hợp với quy mô của doanh nghiệp tương ứng.

Từ khóa. Kế toán quản trị, nhân tố quy mô doanh nghiệp, ảnh hưởng, doanh nghiệp nhỏ và vừa (DNNVV)

\section{THE IMPACT OF SIZE FACTOR ON THE IMPLEMENTATION OF MANAGEMENT ACCOUNTING IN VIETNAMESE SMALL AND MEDIUM ENTREPRISES}

\begin{abstract}
During the world integration progress, Vietnamese enterprises (including small and medium enterprises) have been faced with not only opportunities but also challenges: being eliminated or being innovating to catch up the world development process. The changes should include about structure, strategy and philosophy management in order to help enterprises to become more adaptable, respond to customers' requirements more quickly by making the timely decisions (Langfield-Smith et al., 2009). With small sizes and not familiar with modern management tools (such as management accounting), they have always got disadvantages in completing with oversea big enterprises or multinational groups. Basing on theory of management accounting, this paper use some tools such as Chi square test, EFA analysis in order to find out the impact of size factor to the possibility of implement management accounting in Vietnamese SMEs.
\end{abstract}

Keywords. management accounting, size factor, impact, small and medium enterprises (SMEs)

\section{1. ĐặT VẤn Đî̀}

Hầu hết các cuộc cách mạng về sự thay đổi khái niệm KTQT có thể phát triển dựa trên ba trường phái chính; đó là việc phát triển từ các khái niệm của Viện KTQT Hoa Kỳ (IMA), Viện điều lệ KTQT (CIMA) và Hiệp hội kế toán quốc tế (IFAC).

Vào năm 1981, IMA đưa ra khái niệm đầu tiên của mình về KTQT dựa trên sự phản ánh về nhu cầu thay đổi của DN đối với thông tin kế toán; tuy nhiên gần đây nhất vào 2008, IMA đưa ra khái niệm về công việc của KTQT là: “... một công việc chuyên nghiệp có liên quan đến việc tham gia vào quá trình ra quyểt định, đề ra kế hoạch và hệ thống thực hiện, đồng thời cung cấp nhũng báo cáo tài chính chuyên nghiệp, giúp các nhà quản trị kiểm soát trong việc tạo lập và thực hiện chiến lược của tổ chức" (Anthony A.Atkinson và ctg., 2012). Sự thay đổi về mặt khái niệm KTQT của IMA phản ánh xu hướng thay đổi vai trò của KTQT ngày càng thể hiện vai trò là một nhân tố của chiến lược kinh doanh nhằm giúp DN quản trị hiệu suất $\mathrm{DN}$, lập kế hoạch và dự toán, quản trị rủi ro, kiểm soát nội bộ, lập báo cáo tài chính ở những thời 
điểm có sự thay đổi lớn, và thể hiện vai trò chuyên gia trong các phương pháp quản trị chi phí (IMA, 2008). Còn theo CIMA (CIMA, 1986, 10) thì đưa ra khái niệm về KTQT như là việc cung cấp thông tin cho các nhà quản trị nhằm các mục đích: tạo lập các chính sách, hoạch định và kiểm soát các hoạt động của $\mathrm{DN}$, ra quyết định dựa trên các lựa chọn khác nhau, việc chuẩn bị các báo cáo tài chính cho các nhóm đối tượng bên ngoài như cổ đông, chủ nợ, các cơ quan thuế... Sau này trong quá trình hiệu chỉnh lại các thuật ngữ KTQT $($ CIMA, 2005, 18) thì vai trò của KTQT đã có nhiều bước tiến và thể hiện một vai trò rộng hơn. Nó được khái niệm lại như là việc áp dụng các nguyên lý kế toán và quản trị tài chính nhằm tạo ra, bảo vệ, duy trì lâu dài và gia tăng giá trị của cổ động và các bên có liên quan trong các $\mathrm{DN}$ hoạt động vì lợi nhuận và phi lợi nhuận, trong khu vực tư nhân hay khu vực công. Theo đó, CIMA đã khái niệm lại KTQT một cách chi tiết hơn, nhấn mạnh rằng KTQT là một phần quan trọng của quá trình quản trị trong đó bao gồm việc nhận diện, tạo ra, trình bày, diễn giải các thông tin thích hợp. Sự thay đổi về khái niệm KTQT của CIMA thể hiện rằng KTQT đã tiến đến gần hơn mối quan tâm của các nhà quản trị cấp cao về việc tập trung vào tính hiệu quả, hoạch định chiến lược và tạo ra giá trị. Và đến nay, xu hướng của năm 2015 thì CIMA đã đưa ra khái niệm KTQT đơn giản là bao hàm kế toán, tài chính và quản trị với những công cụ quản lý hàng đầu (CIMA, 2015). Tương tự IFAC đưa ra khái niệm lần đầu vào năm 1989 thì KTQT “... là một quá trình nhận diện, đo luờng, tổng hợp, phân tích, chuẩn bị, diê̂n giải và truyền đạt các thông tin (cả về tài chính lẫn hoạt động) được sử dưng bởi các nhà quản lý nhằm mục đích hoạch định, đo luờng và kiểm soát một tổ chức, và để đảm bảo rằng nguồn lực của tổ chức đó được sử dụng một cách phù hợ và có trách nhiệm". Khái niệm này cũng tương tự như khái niệm truyền thống ban đầu của các tổ chức khác như IMA. Tuy nhiên sau đó 9 năm, vào năm 1998 thì IFAC đã hiệu chỉnh lại, mở rộng đáng kể vai trò của KTQT trong khái niệm mới của mình. Theo đó, KTQT được xem xét như các hoạt động gắn bó, đan xen với tất cả các hoạt động quản trị của tổ chức. Hay nói cách khác, KTQT hướng đến vai trò quản trị nhằm tập trung vào việc tạo ra giá trị cho tổ chức bằng cách sử dụng hiệu quả các nguồn lực với các con người năng động trong những tình huống cạnh tranh. Và sau này theo khái niệm mới về KTQT của IFAC (2002) thì “...KTQT huớng về các quá trình xử lý và kỹ thuật, tập trung vào việc sử dụng một cách có hiệu quả và hiệu suất nhũng nguồn lực của tổ chức, giúp hỗ trợ các nhà quản lý hoàn thành nhiệm vu gia tăng giá trị cho khách hàng cũng nhu cổ đông" (Langfield-Smith \& ctg., 2009, 6). Theo luật kế toán Việt Nam, KTQT được định nghĩa là “... việc thu thập, xử lý, phân tích và cung cấp thông tin kinh tế, tài chính theo yêu cầu quản trị và quyết định kinh tế, tài chính trong nội bộ đơn vị kế toán" (Luật kế toán, khoản 3, điều 4).

Ngày nay trong các doanh nghiệp, KTQT ngày càng đóng vai trò quan trọng trong công tác quản lý. Theo IFAC thì vai trò KTQT thể hiện như một phần không thể tách rời của quy trình quản trị với vai trò cung cấp thông tin cần thiết để kiểm soát những hoạt động hiện tại của $\mathrm{DN}$, hoạch định chiến lược, chiến thuật và hoạt động tương lai của $\mathrm{DN}$; tối ưu hóa việc sử dụng các nguồn lực; đo lường và đánh giá hoạt động của $\mathrm{DN}$; giảm thiểu tính chủ quan trong quá trình ra quyêt định và cải thiện hoạt động giao tiếp trong và ngoài $\mathrm{DN}$ (IFAC, 1998,99). Hầu hết các lý thuyết của KTQT đều đề cập đến các chức năng như hoạch định, kiểm soát, đánh giá hiệu quả quản lý, cải thiện và phát triển các chiến lược cạnh tranh, ra quyết định như là những chức năng chính của KTQT để đạt được mục tiêu của công ty (Scapens, 1991; Weetman, 1999; Upchurch, 1998; Atkinson và ctg., 2001). Theo Ersnt \& Young và IMA thì “... Các kế toán quản trị viên ngày càng được xem nhu là nhũng nhà đối tác kinh doanh chứ không còn đơn thuần là nhũng ngườ giữ số sách nhu trước kia nữa, và ho ngày càng tập trung nhiều hơn vào các vấn đề chiến lược chính, vượt ra khỏi giới hạn của kế toán tài chính ..." (Ersnt \& Young và IMA, 2003, 1). Điều này thể hiện ở việc vai trò của các nhân viên kế toán quản trị ngày càng thoát ly ra khỏi chức năng truyền thống từ người "giữ sổ sách" hay "người kiểm soát" chuyển dần sang vai trò hỗ trợ kinh doanh hay nhà tư vấn kinh doanh nội bộ. Trong nghiên cứu của mình gần đây, Valančienè và Gimžauskienè (2007) đã kết luận rằng KTQT hiện đại mở rộng vai trò từ tích hợp số liệu sang vai trò cung cấp thông tin cho việc triển khai chiến lược. Và trọng tâm trước đây của KTQT là hướng đến cổ đông thì giờ hướng đến tổ hợp giải pháp hướng đến cả khách hàng - nhân viên - cổ đông. Nhóm giải pháp này hướng đến việc giám sát thường xuyên, đo lường và quản trị lợi thế chiến lược và kết quả trong tương lai (bằng cách phân bổ chiến lược thành những mục tiêu phù hợp, những thước đo cụ thể bằng bản đồ chiến lược).

Hệ thống KTQT là một hệ thống thông tin nơi tạo ra các thông tin để đáp ứng yêu cầu của các nhà quản trị nhằm mục đích tạo ra giá trị và quản lý các nguồn lực. Nó góp phần tạo nên một hệ thống thông tin rộng khắp toàn $\mathrm{DN}$, bao gồm các thông tin thường xuyên cũng như các thông tin phục vụ cho các mục 
đích đặc biệt như đánh giá, đo lường, hoạch định, kiểm soát một hoặc nhiều loại sản phẩm, dịch vụ nào đó. Chính vì vậy, hệ thống thông tin KTQT không thể có khả năng đáp ứng được toàn bộ các yêu cầu về thông tin của các nhà quản trị để ra quyết định, thay vào đó những thông tin này có thể phải tìm kiếm từ những nguồn khác, thậm chí là bên ngoài DN (Langfield-Smith 2012, 6-9).

Cho đến nay, trên thế giới vẫn chưa có sự thống nhất về khái niệm thế nào gọi là DNNVV, mà khái niệm này được xác định bởi các tiêu chí khác nhau theo từng quốc gia, từng ngành công nghiệp khác nhau. Do đó, khái niệm DNNVV trên thế giới có thể được xác định bởi các tiêu thức như: vị trí địa lý, quy mô, số năm thành lập, cấu trúc $\mathrm{DN}$, số lượng nhân viên, doanh thu, tài sản ròng, cấu trúc sở hữu, đổi mới công nghệ ... (Deros và ctg., 2006). Ở Việt Nam, theo nghị định số 56/2009/NĐ-CP của Chính Phủ ban hành ngày 30 tháng 6 năm 2009, DNNVV được chia theo ngành, bao gồm: nông, lâm nghiệp và thủy sản; công nghiệp và xây dựng; thương mại và dịch vụ. Bên cạnh đó, tiêu thức chủ yếu để phân loại DNNVV ở Việt Nam là số lao động và số vốn, tuy nhiên cũng không nói rõ là số lao động bình quân hay số lao động tại thời điểm phân loại (vì đây là một tiêu thức gần như liên tục biến động trong năm kinh doanh); cũng như chưa phân biệt rõ được số vốn là vốn kinh doanh đăng ký trên giấy phép hay vốn hoạt động bình quân của DN.

\begin{tabular}{|c|c|c|c|c|c|}
\hline \multirow{2}{*}{$\begin{array}{l}\text { Quy mô } \\
\text { Khu vực }\end{array}$} & \multirow{2}{*}{$\begin{array}{c}\begin{array}{c}\text { Doanh nghiệp } \\
\text { siêu nhỏ }\end{array} \\
\text { Số lao động }\end{array}$} & \multicolumn{2}{|c|}{ Doanh nghiệp nhỏ } & \multicolumn{2}{|c|}{ Doanh nghiệp vừa } \\
\hline & & $\begin{array}{c}\text { Tổng nguồn } \\
\text { vốn }\end{array}$ & Số lao động & Tổng nguồn vốn & Số lao động \\
\hline $\begin{array}{l}\text { I. Nông, lâm } \\
\text { nghiệp và thủy } \\
\text { sản }\end{array}$ & $\begin{array}{l}10 \text { người trở } \\
\text { xuống }\end{array}$ & $\begin{array}{l}20 \text { tỷ đồng trở } \\
\text { xuống }\end{array}$ & $\begin{array}{l}\text { từ trên } 10 \text { người } \\
\text { dến } 200 \text { người }\end{array}$ & $\begin{array}{l}\text { từ trên } 20 \text { tỷ đồng } \\
\text { đến } 100 \text { tỷ đồng }\end{array}$ & $\begin{array}{l}\text { từ trên } 200 \\
\text { người đến } 300 \\
\text { người }\end{array}$ \\
\hline $\begin{array}{l}\text { II. Công nghiệp } \\
\text { và xây dựng }\end{array}$ & $\begin{array}{l}10 \text { người trở } \\
\text { xuống }\end{array}$ & $\begin{array}{l}20 \text { tỷ đồng trở } \\
\text { xuống }\end{array}$ & $\begin{array}{l}\text { từ trên } 10 \text { người } \\
\text { đến } 200 \text { người }\end{array}$ & $\begin{array}{l}\text { từ trên } 20 \text { tỷ đồng } \\
\text { đến } 100 \text { tỷ đồng }\end{array}$ & $\begin{array}{l}\text { từ trên } 200 \\
\text { người đến } 300 \\
\text { người }\end{array}$ \\
\hline $\begin{array}{l}\text { III. Thương mại } \\
\text { và dịch vụ }\end{array}$ & $\begin{array}{l}10 \text { người trở } \\
\text { xuống }\end{array}$ & $\begin{array}{l}10 \text { tỷ đồng trở } \\
\text { xuống }\end{array}$ & $\begin{array}{l}\text { từ trên } 10 \text { người } \\
\text { đến } 50 \text { người }\end{array}$ & $\begin{array}{l}\text { từ trên } 10 \text { tỷ đồng } \\
\text { đến } 50 \text { tỷ đồng }\end{array}$ & $\begin{array}{l}\text { từ trên } 50 \\
\text { người đến } 100 \\
\text { người }\end{array}$ \\
\hline
\end{tabular}

Nguồn: Nghị định số 56/2009/NĐ-CP của Chính Phủ ban hành ngày 30 tháng 6 năm 2009

Nhìn chung, các DNNVV tại Việt Nam có một số đặc điểm nổi bật như: chủ yếu là DN ngoài quốc doanh, trình độ năng lực quản lý của các nhà quản trị ở DNNVV cũng như trình độ tay nghề của người lao động còn thấp, áp dụng công nghệ lạc hậu, năng suất thấp, khả năng tiếp cận và gia nhập thị trường của DNNVV còn thấp, có quy mô nhỏ xét về chỉ tiêu số lượng lao động và khả năng tài chính còn hạn chế ...

Xét về tổng thể, với hệ thống chính trị tương đối ổn định, nên hầu như các DN Việt Nam nói chung và các DNNVV nói riêng không bị ảnh hưởng nhiều do sự bất ổn của việc thay đổi từ các chính sách điều hành vi mô - vĩ mô tác động. Thời gian qua cũng như sắp tới, cùng với hàng loạt hiệp định thương mại chuẩn bị được ký kết như TPP, các FTA ký kết giữa khối ASEAN và EU, RCEP (ASEAN+6), giữa Việt Nam và Hàn Quốc, Nhật Bản ... sẽ tạo ra hàng loạt cơ hội giao thương làm ăn cho các DN Việt Nam nói chung và các DNNVV nói riêng. Bên cạnh đó, lực lượng lao động của Việt Nam thuộc thành phần lao động trẻ, có tri thức, được đào tạo bài bản tại các trường đại học, cao đẳng chuyên nghiệp ngày càng nhiều. Điều này giúp cho các DNNVV thuận lợi trong việc trẻ hóa và nâng cao trình độ năng lực đội quản trị của $\mathrm{DN}$ mình, mà còn có thể tận dụng được nguồn nhân công giá rẻ.

Về mặt khó khăn, do ảnh hưởng tình hình kinh tế toàn cầu nói chung cũng như nền kinh tế Việt Nam nói riêng, các DNNVV tại Việt Nam cũng phải đối mặt với rất nhiều khó khăn thách thức. Các khó khăn xuất phát không chỉ từ phía áp lực cạnh tranh từ bên ngoài, mà còn xuất phát từ nội tại của chính các $\mathrm{DN}$. Xét về tổng thể, tình hình kinh tế - xã hội năm 2014 diễn ra trong bối cảnh kinh tế thế giới hồi phục chậm và không đồng đều giữa các nền kinh tế sau suy thoái toàn cầu. Ngoài ra, tình hình giao thương với một số quốc gia trên thế giới như Nga, các nước trong khối liên minh $\mathrm{EU}$... ít nhiều bị tác động bởi tình hình chính trị bất ổn tại một số quốc gia, nhất là khu vực châu Âu dẫn đến kinh doanh trong lĩnh vực thương mại 
và công nghiệp cũng như xuất khẩu của khu vực đồng EURO bị ảnh hưởng mạnh bởi các biện pháp trừng phạt kinh tế giữa các nước trong khu vực.

Mặc dù các DNNVV đóng vai trò quan trọng cả về mặt kinh tế và xã hội, tuy nhiên trên thế giới việc nghiên cứu về KTQT tại DNNVV được đánh giá là chưa đầy đủ (Marriott \& Marriott, 2000; Mitchell \& Reid, 2000). Các nghiên cứu liên quan đến việc vận dụng KTQT trong các DNNVV có thể tóm tắt ở một số mảng như sau:

Thư nhất, các nghiên cứu tổng thể liên quan về sự thay đổi và nguyên nhân dẫn đến sự thay đổi trong việc vận dụng KTQT trong các DN nói chung qua các giai đoạn phát triển của KTQT.

Thứ hai, các nghiên cứu liên quan về việc vận dụng KTQT trong các DNVVV.

Thứ $b a$, nghiên cứu về các nhân tố tác động đến việc vận dụng KTQT trong các DN nói chung và DNNVV nói riêng.

Từ các kết quả nghiên cứu về việc vận dụng KTQT trên thế giới, có thể rút ra và tổng hợp một số mô hình các nhân tố tác động đến việc vận dụng KTQT như sau:

Thứ nhất, quy mô DN là một nhân tố quan trọng được cho là có sự tác động đến cả cấu trúc lẫn các sự sắp xếp về mặt kiểm soát trong $\mathrm{DN}$.

Thư hai, nhân tố mức độ cạnh tranh của thị trường cũng được nhiều nhà nghiên cứu đề cập đến mặc dù kết quả trái ngược nhau.

Thứ $b a$, nhân tố thiết kế tổ chức phân quyền được kiểm định chỉ ra tác động đến việc vận dụng KTQT theo hướng là trong DN có tổ chức phân quyền thì lựa chọn các công cụ kỹ thuật KTQT phức tạp hơn so với $\mathrm{DN}$ có tổ chức tập quyền.

Thư tư, nhân tố nguồn lực khách hàng được kiểm định chỉ ra tác động đến việc vận dụng KTQT theo hướng là khi $\mathrm{DN}$ phải đối mặt với nguồn lực khách hàng càng mạnh thì càng phải lựa chọn vận dụng KTQT ở mức độ phức tạp hơn nhằm cải thiện quá trình ra quyết định và kiểm soát, để có thể đáp ứng được việc duy trì sự thỏa mãn yêu cầu của khách hàng (Abdel-Kader và Luther, R., 2008).

Thư năm, nhân tố tỷ lệ sở hữu của nhà đầu tư ngoại trong $\mathrm{DN}$ được kiểm định chỉ ra tác động đến việc vận dụng KTQT theo hướng là khi có sự tham gia của của các nhà đầu tư ngoại, $\mathrm{DN}$ sẽ sử dụng nhiều công cụ kỹ thuật KTQT hơn so với những DN không có sự tham gia của các nhà đầu tư ngoại.

Thư sáu, nhân tố ngành nghề kinh doanh/các nhân tố kỹ thuật sản xuất tiên tiến (ATM), kỹ thuật quản trị toàn diện $(\mathrm{TQM})$, kỹ thuật quản trị Just in time ... theo lý thuyết ngẫu nhiên đó là các nhân tố quan trọng tác động đến việc vận dụng KTQT.

Thư bảy, nhân tố nhận thức về sự bất ổn của môi trường tác động đến việc vận dụng KTQT theo hướng là khi $\mathrm{DN}$ đối mặt với sự bất ổn cao của môi trường thì $\mathrm{DN}$ có xu hướng áp dụng tổ chức phân quyền, và kết quả là phải vận dụng KTQT ở mức độ phức tạp hơn.

Thứ tám, khi nghiên cứu về tác động của nhân tố văn hóa $\mathrm{DN}$ đến việc vận dụng KTQT, AlperErserim (2012) đã chỉ ra rằng các loại hình văn hóa $\mathrm{DN}$ như: văn hóa hỗ trợ; văn hóa cải tiến và văn hóa quản lý theo mục tiêu có tác động đến việc vận dụng KTQT.

Thư chín, khi nghiên cứu về nhân tố chiến lược kinh doanh, rất nhiều tác giả đã chỉ ra rằng có sự tác động của nhân tố này lên việc vận dụng KTQT (Langfield-Smith, 1998b; Baines \&Langfield-Smith, 2003; Tuan Zainun Tuan Mat 2010).

Thư mười, trong DNNVV sự hiện diện của các nhân viên kế toán có đủ trình độ chuyên môn là một nhân tố quan trọng tác động đến việc vận dụng KTQT.

Tại Việt Nam, theo các khảo sát, nghiên cứu về việc áp dụng KTQT vào DN Việt Nam nói chung và DNNVV nói riêng trong một giai đoạn dài từ 1997 cho đến 2010 (Phạm Văn Dược, 1997; Trần Anh Hoa, 2003; Phạm Ngọc Toàn, 2010) thì các DN chưa chú trọng đến việc vận dụng các công cụ kỹ thuật của KTQT vào hoạt động quản lý $\mathrm{DN}$, thậm chí ở một số các $\mathrm{DNNVV}$ còn chưa có khái niệm về vận dụng KTQT hoặc chưa có bộ máy KTQT riêng biệt để phục vụ cho nhu cầu quản trị của $\mathrm{DN}$. Sau đó vào năm 2012, Đoàn Ngọc Phi Anh khi tiến hành khảo sát trên 220 các DN Việt Nam với quy mô vừa và lớn đã chỉ ra một số nhân tố như yếu tố cạnh tranh càng cao, phân cấp quản lý càng lớn thì càng khiến cho các $\mathrm{DN}$ có xu hướng sử dụng càng nhiều các công cụ của KTQT chiến lược (SMA); và khi DN sử dụng càng nhiều công cụ của SMA thì thành quả về cả hai mặt tài chính - phi tài chính đạt được càng cao (Đoàn Ngọc Phi Anh, 2012). 


\section{THỰC TRẠNG KHẢ NĂNG VẬN DỤNG KTQT TẠI CÁC DNNVV VIỆT NAM}

\subsection{Thực trạng}

Tác giả tiến hành gửi 350 bảng câu hỏi khảo sát đến các DNNVV và thu về được 303 bảng trả lời câu hỏi. Kết quả sau khi thu thập và loại bỏ các phiếu khảo sát không đạt yêu cầu (vd. phiếu không điền đầy đủ thông tin ..vv..), còn lại 290 phiếu đạt yêu cầu.

Mục đích của đợt khảo sát là nhằm đo lường mức độ tác động của các nhân tố đến khả năng vận dụng KTQT trong các DNNVV tại Việt Nam, do vậy đối tượng của đợt khảo sát này là các DNNVV đã, đang hoặc sẽ có khả năng vận dụng KTQT. Để khảo sát nhằm xem xét liệu có hay không sự tác động giữa việc vận dụng KTQT trong $\mathrm{DN}$ với quy mô $\mathrm{DN}$, tác giả sử dụng kiểm định Chi bình phương (Chi - square test). Ta có bảng định nghĩa các biến như sau:

\begin{tabular}{|l|l|l|}
\hline STT & Tên biến & Biến định tính \\
\hline 1 & QMO & $\begin{array}{l}\text { Quy mô DN } \\
\text { Siêu nhỏ }=1 \text {, Nhỏ }=2 \text {, Vừa }=3\end{array}$ \\
\hline 2 & KTQT & $\begin{array}{l}\text { Vận dụng KTQT trong DNNVV Việt Nam } \\
\text { Có }=1 \text {, Không }=0\end{array}$ \\
\hline
\end{tabular}

Theo kết quả khảo sát sơ bộ ban đầu, tiến hành sử dụng kiểm định Chi bình phương (Chi - square test) ta có các kết quả như sau:

Vận dụng KTQT trong DNNVV Việt Nam * Quy mô doanh nghiệp Crosstabulation

\begin{tabular}{|c|c|c|c|c|c|c|}
\hline & & & \multicolumn{3}{|c|}{ Quy mo doanh nghiep } & \multirow[t]{2}{*}{ Total } \\
\hline & & & Sieu nho & Nho & Vua & \\
\hline \multirow{4}{*}{$\begin{array}{l}\text { Vận dung KTQT } \\
\text { trong DNNVV } \\
\text { Việt Nam }\end{array}$} & \multirow{2}{*}{ Không } & Count & 66 & 27 & 11 & 104 \\
\hline & & $\%$ within Quy mo doanh nghiep & $98,5 \%$ & $42,9 \%$ & $6,9 \%$ & $35,9 \%$ \\
\hline & \multirow{2}{*}{ Có } & Count & 1 & 36 & 149 & 186 \\
\hline & & $\%$ within Quy mo doanh nghiep & $1,5 \%$ & $57,1 \%$ & $93,1 \%$ & $64,1 \%$ \\
\hline \multirow{2}{*}{\multicolumn{2}{|c|}{ Total }} & Count & 67 & 63 & 160 & 290 \\
\hline & & $\%$ within Quy mo doanh nghiep & $100,0 \%$ & $100,0 \%$ & $100,0 \%$ & $100,0 \%$ \\
\hline
\end{tabular}

Bảng kiểm định thang đo bằng hệ số tin cậy Cronbach Alpha

\begin{tabular}{|l|l|l|r|r|r|r|}
\hline \multirow{3}{*}{$\begin{array}{l}\text { Vận dung KTQT } \\
\text { trong DNNVV }\end{array}$} & \multirow{2}{*}{$\begin{array}{l}\text { Không } \\
\text { Việt Nam }\end{array}$} & Count & 66 & 27 & 11 & 104 \\
\cline { 2 - 6 } & \multirow{2}{*}{ Có } & \% within Quy mo doanh nghiep & $98,5 \%$ & $42,9 \%$ & $6,9 \%$ & $35,9 \%$ \\
\hline \multirow{3}{*}{ Total } & Count & 1 & 36 & 149 & 186 \\
\cline { 2 - 6 } & & \% within Quy mo doanh nghiep & $1,5 \%$ & $57,1 \%$ & $93,1 \%$ & $64,1 \%$ \\
\hline & Count & 67 & 63 & 160 & 290 \\
\cline { 2 - 6 } & & \% within Quy mo doanh nghiep & $100,0 \%$ & $100,0 \%$ & $100,0 \%$ & $100,0 \%$ \\
\hline
\end{tabular}

\section{Kết quả kiểm định Chi-Square(Chi-Square Tests)}

\begin{tabular}{|l|r|r|r|}
\hline & Value & df & Asymp. Sig. (2-sided) \\
\hline Pearson Chi-Square & $174,104^{\mathrm{a}}$ & 2 &, 000 \\
\hline Likelihood Ratio & 201,953 & 2 &, 000 \\
\hline Linear-by-Linear Association & 171,524 & 1 &, 000 \\
\hline N of Valid Cases & 290 & & \\
\hline
\end{tabular}

a. 0 cells $(0,0 \%)$ have expected count less than 5 . The minimum expected count is 22,59 . 
Từ số liệu có được từ kiểm định Chi-Square, tác giả thống kê kết quả ban đầu như sau:

Bảng kết quả khảo sát về quy mô DN

\begin{tabular}{|l|c|c|}
\hline \multicolumn{1}{|c|}{ Chỉ tiêu khảo sát } & Số lượng DN & \% \\
\hline DN siêu nhỏ & 67 & 23,1 \\
\hline DN nhỏ & 63 & 21,7 \\
\hline DN vừa & 160 & 55,2 \\
\hline Tổng cộng & $\mathbf{2 9 0}$ & $\mathbf{1 0 0}$ \\
\hline
\end{tabular}

Bảng kết quả khảo sát về thực trạng vận dụng KTQT trong DN

\begin{tabular}{|l|c|c|}
\hline \multicolumn{1}{|c|}{ Chỉ tiêu khảo sát } & Số lượng DN & \% \\
\hline Không triển khai & 104 & 35,9 \\
\hline Có triển khai & 186 & 64,1 \\
\hline Tổng cộng & $\mathbf{2 9 0}$ & $\mathbf{1 0 0}$ \\
\hline
\end{tabular}

Kết quả trên cho thấy trong số 186 DNNVV Việt Nam xác nhận có vận dụng KTQT tại DN thì loại hình $\mathrm{DN}$ quy mô vừa chiếm tỷ trọng áp đảo đến $80,1 \%$ (tương ứng với $149 \mathrm{DN}$ ), kế tiếp là $\mathrm{DN}$ nhỏ với tỷ lệ 19,4\% (tương ứng với $36 \mathrm{DN}$ ). Số DN siêu nhỏ có vận dụng KTQT chiếm tỷ lệ cực kỳ khiêm tốn với tỷ lệ $0,5 \%$ (tương ứng với $1 \mathrm{DN}$ ). Ngược lại trong số $104 \mathrm{DNNVV}$ Việt Nam xác nhận không có vận dụng KTQT tại DN thì loại hình DN quy mô siêu nhỏ chiếm tỷ trọng áp đảo đến $63,5 \%$ (tương ứng với $66 \mathrm{DN}$ ), kế tiếp là $\mathrm{DN}$ nhỏ với tỷ lệ $26 \%$ (tương ứng với $27 \mathrm{DN}$ ). Số $\mathrm{DN}$ vừa không có vận dụng $\mathrm{KTQT}$ chiếm tỷ lệ cực kỳ khiêm tốn với tỷ lệ $10,5 \%$ (tương ứng với $11 \mathrm{DN}$ ).

Ngoài ra, theo kết quả khảo sát ở trên, giá trị Sig. $=0,00<0,01$ nên kết luận là việc vận dụng KTQT và nhân tố quy mô $\mathrm{DN}$ có mối liên hệ với độ tin cậy $99 \%$.

Như vậy trong các DNNVV hoạt động tại Việt Nam thì xu hướng thể hiện khá rõ mối liên hệ tỷ lệ thuận giữa quy mô $\mathrm{DN}$ và việc lựa chọn vận dụng KTQT như là công cụ quản lý theo chiều hướng là doanh nghiệp có quy mô càng lớn thì nhu cầu và xu thế quản trị càng cao và phức tạp, nên việc lựa chọn KTQT như là phương tiện quản lý được nhiều doanh nghiệp chấp nhận.

\subsection{Mức độ ảnh hưởng của nhân tố quy mô đến khả năng vận dụng KTQT trong DNNVV}

Bảng kiểm định thang đo bằng hệ số tin cậy Cronbach Alpha

\begin{tabular}{|l|r|r|r|r|}
\hline Biến quan sát & $\begin{array}{c}\text { Trung bình thang đo } \\
\text { nếu loại biến }\end{array}$ & $\begin{array}{c}\text { Phương sai thang đo } \\
\text { nếu loại biến }\end{array}$ & $\begin{array}{c}\text { Tương quan } \\
\text { biến tồng }\end{array}$ & $\begin{array}{c}\text { Cronbach Alpha nếu } \\
\text { loại biến này }\end{array}$ \\
\hline \multicolumn{5}{|c|}{ Quy mô doanh nghiệp (SIZE), Alpha = 0,751 } \\
\hline SIZE1 & 6,28 & 1,768 &, 654 &, 604 \\
\hline SIZE2 & 6,81 & 1,351 &, 582 &, 693 \\
\hline SIZE3 & 6,34 & 1,824 &, 541 &, 711 \\
\hline
\end{tabular}

Sau khi tiến hành thảo luận với các chuyên gia trong lĩnh vực kế toán, là những người có kinh nghiệm trong việc vận dụng KTQT trong các doanh nghiệp như kế toán trưởng, giám đốc tài chính, tổng giám đốc, chuyên viên tư vấn, những người tham gia giảng dạy lâu năm về KTQT trong các trường đại học ..... chúng tôi tiến hành xây dựng các thang đo và các biến quan sát sử dụng thang điểm Likert ( 5 mức độ) nhằm xác định những yếu tố tác động đến tính khả thi của việc vận dụng KTQT trong các DNNVV. Bằng cách sử dụng các phương pháp phân tích nhân nhân tố khám phá (EFA) và phân tích hồi quy đa biến, kết quả của khảo sát chỉ ra rằng quy mô của DNNVV tương thích với mức độ khả thi của việc vận dụng KTQT theo hướng là quy mô $\mathrm{DN}$ càng lớn thể hiện qua doanh thu, số lượng nhân viên hoạt động bình quân, số lượng các phòng ban với chức năng rõ ràng, độc lập thì khả năng thành công cao hơn.

Với nhân tố quy mô doanh nghiệp, chúng tôi xây dựng thang đo với ba biến quan sát bao gồm SIZE1Doanh thu của DN; SIZE2 - Số lượng nhân viên của DN và SIZE3 - Số lượng các phòng ban, chi nhánh của $\mathrm{DN}$. Sau khi kiểm định cho thấy thang đo quy mô doanh nghiệp (SIZE) được đo lường qua 3 biến quan 
sát với kết quả phân tích đáp ứng độ tin cậy của thang đo (Cronbach Alpha) là 0,751 và hệ số tương quan biến tổng lớn hơn 0,3 .

Với kết quả KMO thu được bằng 0,790 (thỏa mãn tiêu chí $0,5 \leq \mathrm{KMO} \leq 1$ ), nên kết luận là phân tích yếu tố là thích hợp với dữ liệu thực tế, ngoài ra các biến quan sát có tương quan tuyến tính với nhân tố đại diện do Sig. $=0,000 \leq 0,5$ (Đinh Phi Hồ, 2012).

KMO and Bartlett's Test

\begin{tabular}{|l|l|r|}
\hline \multicolumn{2}{|l|}{ Kaiser-Meyer-Olkin Measure of Sampling Adequacy. } &, 790 \\
\hline \multirow{3}{*}{ Bartlett's Test of Sphericity } & Approx. Chi-Square & 4276,073 \\
\cline { 2 - 3 } & df & 406 \\
\cline { 2 - 3 } & Sig. &, 000 \\
\hline
\end{tabular}

Tiếp tục kiểm định phương sai trích (\% cumulative variance) của các yếu tố, ta thấy trong Bảng tổng phương sai được giải thích (Total Variance Explained), phương sai cộng dồn của các yếu tố (cumulative \%) là 70,13\%, thỏa mãn tiêu chuẩn phương sai trích phải > 50\% (Hair 2009, theo Đinh Phi Hổ 2012). Điều này có nghĩa là $70,13 \%$ thay đổi của các nhân tố được giải thích bởi các biến quan sát (thành phần của Factor). Ngoài ra, theo Gerbing và Anderson (1988), các nhân tố có Eigenvalue $<1$ sẽ không có tác dụng tóm tắt thông tin tốt hơn biến gốc (biến tiềm ẩn trong các thang đo trước khi $\mathrm{EFA}$ ). Vì thế, các nhân tố chỉ được rút trích tại Eigenvalue $>1$ và được chấp nhận khi tổng phương sai trích $\geq 50 \%$. Kết quả nghiên cứu này có 8 nhân tố đại diện đảm bảo được tiêu chuẩn có Eigenvalue $>1$.

Bảng tổng phương sai được giải thích (Total Variance Explained)

\begin{tabular}{|c|c|c|c|c|c|c|c|c|c|}
\hline \multirow{2}{*}{ Component } & \multicolumn{3}{|c|}{ Initial Eigenvalues } & \multicolumn{3}{|c|}{$\begin{array}{c}\text { Extraction Sums of Squared } \\
\text { Loadings }\end{array}$} & \multicolumn{3}{|c|}{$\begin{array}{c}\text { Rotation Sums of Squared } \\
\text { Loadings }\end{array}$} \\
\hline & Total & $\begin{array}{c}\% \text { of } \\
\text { Variance }\end{array}$ & $\begin{array}{c}\text { Cumulative } \\
\% \\
\end{array}$ & Total & $\begin{array}{c}\% \text { of } \\
\text { Variance }\end{array}$ & $\begin{array}{c}\text { Cumulative } \\
\% \\
\end{array}$ & Total & $\begin{array}{c}\% \text { of } \\
\text { Variance }\end{array}$ & $\begin{array}{c}\text { Cumulative } \\
\% \\
\end{array}$ \\
\hline 1 & 6,422 & 22,146 & 22,146 & 6,422 & 22,146 & 22,146 & 3,312 & 11,421 & 11,421 \\
\hline 2 & 3,685 & 12,705 & 34,852 & 3,685 & 12,705 & 34,852 & 2,882 & 9,939 & 21,360 \\
\hline 3 & 2,723 & 9,390 & 44,242 & 2,723 & 9,390 & 44,242 & 2,689 & 9,272 & 30,633 \\
\hline 4 & 2,062 & 7,111 & 51,352 & 2,062 & 7,111 & 51,352 & 2,674 & 9,220 & 39,852 \\
\hline 5 & 1,753 & 6,046 & 57,399 & 1,753 & 6,046 & 57,399 & 2,522 & 8,696 & 48,549 \\
\hline 6 & 1,367 & 4,714 & 62,113 & 1,367 & 4,714 & 62,113 & 2,266 & 7,813 & 56,362 \\
\hline 7 & 1,283 & 4,424 & 66,536 & 1,283 & 4,424 & 66,536 & 2,010 & 6,930 & 63,292 \\
\hline 8 & 1,042 & 3,593 & 70,130 & 1,042 & 3,593 & 70,130 & 1,983 & $\mathbf{6 , 8 3 7}$ & 70,130 \\
\hline 9 & ,914 & 3,152 & 73,282 & & & & & & \\
\hline
\end{tabular}

Tiếp tục kiểm định, theo kết quả $\mathrm{R}^{2}$ hiệu chỉnh (Adjusted $\mathrm{R}$ Square) là 0,348 , có nghĩa là $34,8 \%$ sự thay đổi về khả năng việc vận dụng KTQT tại các DNNVV tại Việt Nam được giải thích bằng 7 biến đại diện độc lập còn lại. 
Bảng tóm tắt mô hình (Model Summaryb)

\begin{tabular}{|c|c|c|c|c|c|c|c|c|c|c|}
\hline \multirow[t]{2}{*}{ Model } & \multirow[t]{2}{*}{$\mathrm{R}$} & \multirow{2}{*}{$\begin{array}{c}\mathrm{R} \\
\text { Square }\end{array}$} & \multirow{2}{*}{$\begin{array}{l}\text { Adjusted } \\
\text { R Square }\end{array}$} & \multirow{2}{*}{$\begin{array}{c}\text { Std. Error } \\
\text { of the } \\
\text { Estimate }\end{array}$} & \multicolumn{5}{|c|}{ Change Statistics } & \multirow{2}{*}{$\begin{array}{l}\text { Durbin- } \\
\text { Watson }\end{array}$} \\
\hline & & & & & $\begin{array}{c}\text { R Square } \\
\text { Change }\end{array}$ & $\begin{array}{c}\mathrm{F} \\
\text { Change }\end{array}$ & df1 & df2 & $\begin{array}{c}\text { Sig. F } \\
\text { Change }\end{array}$ & \\
\hline 1 &, $605^{\mathrm{a}}$ & ,366 & ,348 & ,80718367 & ,366 & 20,320 & 8 & 281 &, 000 & 1,845 \\
\hline
\end{tabular}

a. Predictors: (Constant), REGR factor score 8 for analysis 1, REGR factor score 7 for analysis 1 , REGR factor score 6 for analysis 1, REGR factor score 5 for analysis 1, REGR factor score 4 for analysis 1 , REGR factor score 3 for analysis 1 , REGR factor score 2 for analysis 1 , REGR factor score 1 for analysis 1

b. Dependent Variable: REGR factor score 1 for analysis 2

Ngoài ra các biến độc lập này có Sig. $=0,000(<0,05)$ do đó các biến độc lập có tương quan với biến phụ thuộc.

\section{Bảng phân tích phương sai (ANOVAa)}

\begin{tabular}{|l|l|r|r|r|r|r|}
\hline \multicolumn{2}{|l|}{ Model } & \multicolumn{1}{c|}{ Sum of Squares } & df & Mean Square & F & Sig. \\
\hline \multirow{4}{*}{1} & Regression & 105,916 & 8 & 13,239 & 20,320 &, $000^{\mathrm{b}}$ \\
\cline { 2 - 8 } & Residual & 183,084 & 281 &, 652 & & \\
\cline { 2 - 8 } & Total & 289,000 & 289 & & & \\
\hline
\end{tabular}

a. Dependent Variable: REGR factor score 1 for analysis 2

b. Predictors: (Constant), REGR factor score 8 for analysis 1 , REGR factor score 7 for analysis 1 , REGR factor score 6 for analysis 1, REGR factor score 5 for analysis 1, REGR factor score 4 for analysis 1, REGR factor score 3 for analysis 1, REGR factor score 2 for analysis 1 , REGR factor score 1 for analysis 1 .

Và do phân tích thông qua EFA nên không có hiện tượng đa cộng tuyến (Collinearity Diagnostics). Tiếp tục sử dụng kiểm định Spearman để kiểm tra giữa từng biến độc lập có ý nghĩa thống kê với giá trị tuyệt đối của số dư được chuẩn hóa (Absolute of Standardized residuals, $\mathrm{ABS}$ ). Tiêu chuẩn đánh giá: khi các hệ số tương quan hạng Spearman có mức ý nghĩa $>0,05$ thì có thể kết luận là phương sai của phần dư không thay đổi. Theo kết quả nghiên cứu thì các biến F1, F2, F3, F4, F5, F7 và F8 có Sig. lần lượt là 0,916 , $0,843,0,204,0,548,0,892,0,562$ và $0,940(>0,05)$ như vậy kiểm định Spearman cho biết phương sai phần dư của bảy biến này không đổi và có ý nghĩa về mặt nghiên cứu.

\section{Correlations}

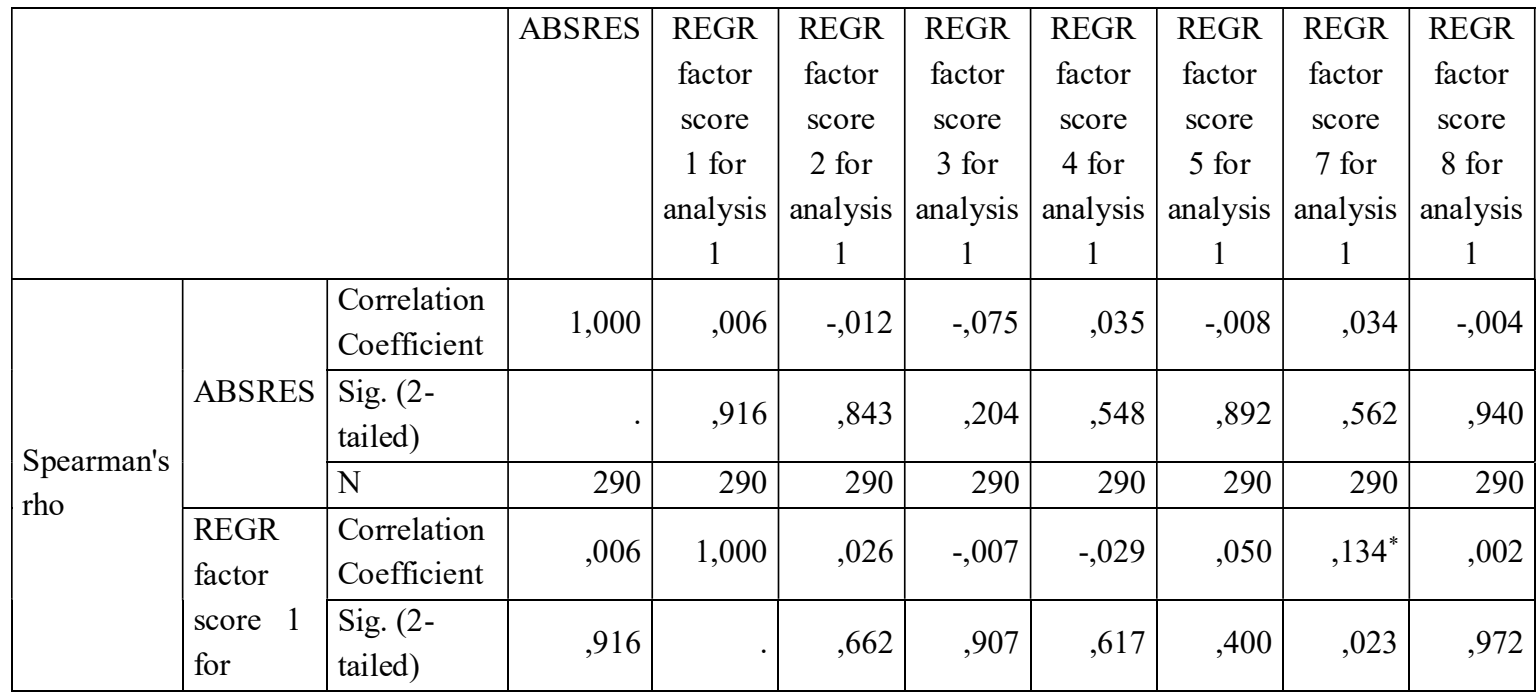




\begin{tabular}{|c|c|c|c|c|c|c|c|c|c|}
\hline $\begin{array}{l}\text { analysis } \\
1\end{array}$ & $\mathrm{~N}$ & 290 & 290 & 290 & 290 & 290 & 290 & 290 & 290 \\
\hline \multirow{3}{*}{$\begin{array}{l}\text { REGR } \\
\text { factor } \\
\text { score } 2 \\
\text { for } \\
\text { analysis } \\
1\end{array}$} & $\begin{array}{l}\text { Correlation } \\
\text { Coefficient }\end{array}$ &,- 012 &, 026 & 1,000 &, 010 &,- 012 &,- 005 &,- 009 &,- 001 \\
\hline & $\begin{array}{l}\text { Sig. (2- } \\
\text { tailed) }\end{array}$ &, 843 & ,662 & &, 866 & ,835 & ,929 & ,885 & ,991 \\
\hline & $\mathrm{N}$ & 290 & 290 & 290 & 290 & 290 & 290 & 290 & 290 \\
\hline \multirow{3}{*}{$\begin{array}{l}\text { REGR } \\
\text { factor } \\
\text { score } 3 \\
\text { for } \\
\text { analysis } \\
1\end{array}$} & $\begin{array}{l}\text { Correlation } \\
\text { Coefficient }\end{array}$ &,- 075 &,- 007 &, 010 & 1,000 &, 016 & ,003 &, 020 &,- 012 \\
\hline & $\begin{array}{l}\text { Sig. (2- } \\
\text { tailed) }\end{array}$ & 204 & ,907 & ,866 & & ,786 & ,955 & ,739 & ,836 \\
\hline & $\mathrm{N}$ & 290 & 290 & 290 & 290 & 290 & 290 & 290 & 290 \\
\hline \multirow{3}{*}{$\begin{array}{l}\text { REGR } \\
\text { factor } \\
\text { score } 4 \\
\text { for } \\
\text { analysis } \\
1\end{array}$} & $\begin{array}{l}\text { Correlation } \\
\text { Coefficient }\end{array}$ &, 035 &,- 029 &,- 012 & ,016 & 1,000 & ,073 &,- 015 & ,033 \\
\hline & $\begin{array}{l}\text { Sig. (2- } \\
\text { tailed) }\end{array}$ &, 548 & 617 & ,835 & ,786 & & ,217 & ,804 &, 578 \\
\hline & $\mathrm{N}$ & 290 & 290 & 290 & 290 & 290 & 290 & 290 & 290 \\
\hline \multirow{3}{*}{$\begin{array}{l}\text { REGR } \\
\text { factor } \\
\text { score } 5 \\
\text { for } \\
\text { analysis } \\
1\end{array}$} & $\begin{array}{l}\text { Correlation } \\
\text { Coefficient }\end{array}$ & -.008 &, 050 &,- 005 & ,003 & 073 & 1,000 &,- 008 & ,009 \\
\hline & $\begin{array}{l}\text { Sig. (2- } \\
\text { tailed) }\end{array}$ & ,892 & ,400 & ,929 & ,955 & ,217 & & ,895 & 877 \\
\hline & $\mathrm{N}$ & 290 & 290 & 290 & 290 & 290 & 290 & 290 & 290 \\
\hline \multirow{3}{*}{\begin{tabular}{|l} 
REGR \\
factor \\
score 7 \\
for \\
analysis \\
1
\end{tabular}} & $\begin{array}{l}\text { Correlation } \\
\text { Coefficient }\end{array}$ & ,034 &, $134^{*}$ &,- 009 &, 020 &,- 015 &,- 008 & 1,000 &,- 002 \\
\hline & $\begin{array}{l}\text { Sig. (2- } \\
\text { tailed) }\end{array}$ &, 562 & 023 & ,885 & ,739 & ,804 & ,895 & & 971 \\
\hline & $\mathrm{N}$ & 290 & 290 & 290 & 290 & 290 & 290 & 290 & 290 \\
\hline \multirow{3}{*}{$\begin{array}{l}\text { REGR } \\
\text { factor } \\
\text { score } 8 \\
\text { for } \\
\text { analysis } \\
1 \\
\end{array}$} & $\begin{array}{l}\text { Correlation } \\
\text { Coefficient }\end{array}$ &,- 004 & ,002 &,- 001 &,- 012 & 033 & ,009 &,- 002 & 1,000 \\
\hline & $\begin{array}{l}\text { Sig. (2- } \\
\text { tailed) }\end{array}$ & 940 & 972 & ,991 & ,836 &, 578 & ,877 & ,971 & \\
\hline & $\mathrm{N}$ & 290 & 290 & 290 & 290 & 290 & 290 & 290 & 290 \\
\hline
\end{tabular}

*. Correlation is significant at the 0,05 level (2-tailed).

Theo kết quả kiểm định thì biến F7 có hệ số 0,562 , quan hệ cùng chiều với biến POSS (là biến khả năng vận dụng KTQT trong các DNNVV). Tức là khi DN đánh giá nhân tố "Quy mô DN (SIZE)" tăng thêm 1 điểm thì mức độ khả thi khi vận dụng KTQT vào DNNVV tăng thêm 0,562 điểm (tương ứng với hệ số tương quan chưa chuẩn hóa là 0,562 ).

Kết quả này cũng phù hợp với một số nghiên cứu trước đây trên thế giới như: Khaled Abed Hutaibat (2005), Abdel-Kader và Luther, R. (2008) cũng như đã được chứng minh qua lý thuyết bất định. Rõ ràng một doanh nghiệp có quy mô lớn thì thông thường đồng nghĩa với tiềm lực kinh tế mạnh, và nhu cầu quản trị cũng cao và phức tạp hơn, điều đó sẽ làm tiền đề tốt cho việc vận dụng KTQT tại doanh nghiệp. Tại Việt Nam khi xét về nhân tố này thì các DNNVV có sự phân hóa rất rõ giữa doanh nghiệp nhỏ (đặc biệt là siêu 
nhỏ) và doanh nghiệp vừa khi xét về tiềm lực quy mô số lượng lao động cũng như doanh thu, do đó khả năng vận dụng KTQT của các đối tượng này cũng rất khác nhau. Và đặc biệt do số lượng lao động dưới 10 người nên việc triển khai bài bản một mô hình KTQT nào cũng có vẻ không cần thiết đối với doanh nghiệp siêu nhỏ, vì thông thường mô hình $\mathrm{DN}$ này chủ yếu đến từ các hộ gia đình kinh doanh nhỏ lẻ, và người chủ DN thường tự mình quyết định tất cả. Tuy nhiên điều này không có nghĩa là không thể vận dụng KTQT cho loại hình $\mathrm{DN}$ này, mà thay vào đó người chủ/người điều hành $\mathrm{DN}$ hay ít nhất là kế toán trưởng phải tự mình trang bị kiến thức về KTQT và vận dụng các công cụ kỹ thuật truyền thống dù là ở mức độ đơn giản nhất. Việc tự mình vận dụng KTQT trong DN siêu nhỏ có thể giúp cho DN giảm bớt rủi ro thông qua các công cụ dự toán, giúp đề ra các kế hoạch kinh doanh hoặc lựa chọn cơ hội kinh doanh, hợp đồng đối tác tốt hơn ... Nhưng mặc khác điều này cũng tạo ra một chi phí cơ hội cho chính $\mathrm{DN}$ đó, do người chủ/người điều hành phải san sẻ bớt thời gian quản lý của mình trong việc vận dụng KTQT thay vì tập trung tìm kiếm cơ hội kinh doanh bên ngoài.

Trong quá trình khảo sát cũng chỉ ra rất rõ ở trên về sự khác nhau giữa tỷ lệ vận dụng KTQT trong các $\mathrm{DN}$ vừa và các $\mathrm{DN}$ nhỏ hoặc siêu nhỏ. Rõ ràng là một $\mathrm{DN}$ với quy mô vừa, với số lượng phòng ban rõ ràng và hoạt động bài bản thì không chỉ có nhu cầu cao về vận dụng KTQT nhằm gia tăng hiệu quả hoạt động mà còn có điều kiện tốt hơn cũng như tiềm lực kinh tế tốt hơn nhằm đáp ứng yêu cầu chi phí khi vận dụng KTQT. Hơn nữa khi một $\mathrm{DN}$ có các phòng ban rõ ràng hoạt động với những chức năng riêng biệt thì nhu cầu về đánh giá hiệu quả từng bộ phận sẽ cao, và đây cũng là động lực nhằm thúc đẩy cho các nhân viên làm việc tốt hơn.

\section{GợI Ý XÂY DỰNG MộT SỐ MÔ HÌNH KTQT tại CÁC DNNVV Việt Nam}

\section{1. Định hướng chung}

Kết quả nghiên cứu chỉ ra rằng quy mô của DNNVV tương thích với mức độ khả thi của việc thành công khi triển khai vận dụng các kỹ thuật KTQT theo hướng là quy mô DN càng lớn thể hiện qua số vốn hoạt động và số lượng nhân viên hoạt động bình quân, với các phòng ban với chức năng rõ ràng, độc lập thì khả năng thành công cao hơn. Do đó khi xét về mối quan hệ lợi ích - chi phí của việc triển khai vận dụng KTQT trong DNNVV, chúng ta cần xem xét kỹ về quy mô của $\mathrm{DN}$, đặc biệt là $\mathrm{DN}$ siêu nhỏ khi quyết định có nên triển khai hay không, và đối với $\mathrm{DN}$ nhỏ và vừa thì nên triển khai đối với mức độ nào, mô hình nào là phù hợp.

\subsection{Biện pháp thực hiện}

a. Đối với các $D N$ siêu nhỏ: với quy mô lao động trên dưới 10 người, với con số này thì việc triển khai mô hình KTQT nào cũng có vẻ không cần thiết, vì thông thường mô hình doanh nghiệp này chủ yếu đến từ các hộ gia đình kinh doanh nhỏ lẻ, và người chủ $\mathrm{DN}$ thường tự mình quyết định tất cả. Tuy nhiên thay vào việc triển khai mô hình KTQT một cách chính thức và bài bản, tác giả khuyến nghị người chủ doanh nghiệp hoặc người điều hành doanh nghiệp nên tự trang bị thêm các kiến thức về KTQT để có thể thực hiện tốt hơn vai trò quản trị trong quá trình điều hành.

b. Đối với các $D N$ nhỏ: với quy mô lao động dưới 50 người đối với loại hình thương mại dịch vụ và có thể đạt đến con số 200 người đối với sản xuất, doanh nghiệp nên bắt đầu triển khai vận dụng bước đầu các kỹ thuật KTQT truyền thống. Một số kỹ thuật hữu ích phục vụ cho công tác quản trị có thể vận dụng đối với nhóm doanh nghiệp này xét về mối quan hệ lợi ích - chi phí là:

Thư nhất, hệ thống dự toán: có thể bao gồm dự toán doanh thu, dự toán chi phí(bao gồm chi phí bán hàng và quản lý doanh nghiệp), dự toán thu - chi tiền, dự toán kết quả kinh doanh. Các hình thức về báo cáo dự toán nói trên tương đổi đơn giản và dễ lập, tuy nhiên doanh nghiệp phải chú trọng chất lượng thông tin đầu vào, đặc biệt là công tác dự báo nhu cầu thị trường tiêu thụ và thông tin về đối thủ cạnh tranh.

Thư hai, phân tích CVP: đây là một kỹ thuật liên quan mật thiết đến quá trình ra quyết định về quyết định giá bán, thương lượng giá bán trong các đơn hàng đặc biệt (thường phát sinh trong quá trình kinh doanh), quyết định về khả năng mua bán hàng hóa để quyết định có nên tiến hành thương vụ hay không thông qua phân tích điểm hòa vốn ... Để phục vụ tốt cho việc phân tích CVP, doanh nghiệp có thể kết hợp với cách phân loại mã chi phí bán hàng và quản lý doanh nghiệp ngay từ đầu vào theo hành vi ứng xử biến phí, định phí hay chi phí hỗn hợp. 
Thư $b a$, trung tâm trách nhiệm: thông thường đối với loại hình doanh nghiệp hoạt động trong lĩnh vực $\mathrm{TM}-\mathrm{DV}$ thì quy mô dưới 50 lao động không cần thiết phải lập báo cáo bộ phận. Với quy mô này thông thường các nhân viên được đánh giá trực tiếp thông qua người quản lý trực tiếp và tổng hợp đánh giá lên cấp quản trị cao nhất. Và các tiêu chí dùng để đánh giá cũng khá đơn giản như doanh số mục tiêu (đối với bộ phận bán hàng), năng lực công tác (đối với bộ phận hỗ trợ như kế toán, nhân sự, kho bãi ...).

c. Đối với các $D N$ vìa: với quy mô lao động trên 200 người, bên cạnh các kỹ thuật KTQT truyền thống doanh nghiệp có thể nghiên cứu triển khai vận dụng thêm một số kỹ thuật của kế toán quản trị chiến lược (SMA) khác như Thẻ Bảng điểm. Một số kỹ thuật hữu ích phục vụ cho công tác quản trị có thể vận dụng đối với nhóm doanh nghiệp này là:

Thư nhất, hệ thống dự toán: tương tự như DN nhỏ.

Thư hai, phân tích CVP: tương tự như DN nhỏ,

Thư $b a$, trung tâm trách nhiệm: khi quy mô có thể lên đến trên 200 lao động thì việc đánh giá hiệu quả không nên làm một cách cảm tính mà nên thực hiện theo định lượng. Đặc biệt đối với các doanh nghiệp có các trung tâm, chi nhánh hoặc bộ phận kinh doanh độc lập thì nhất thiết phải thiết lập hệ thống báo cáo bộ phận để từ đó có thể đánh giá chính xác được hiệu quả kinh doanh và ra quyết định đầu tư. Ngoài ra, theo xu hướng hội nhập việc đánh giá khen thưởng động viên nhân viên ngày càng cần phải được tiến hành một cách chuyên nghiệp, bài bản nhằm động viên tinh thần làm việc để hướng đến kết quả kinh doanh ngày càng tốt hơn. Do đó các nhà quản trị cần kết hợp với kỹ thuật dự toán để làm cơ sở đánh giá chính xác hơn về hiệu quả làm việc của từng bộ phận, từng nhân viên.

Thư tư, các kỹ thuật của SMA: tùy theo nhu cầu và khả năng tài chính cũng như năng lực quản trị ...., các doanh nghiệp quy mô vừa có thể linh hoạt áp dụng thêm các kỹ thuật quản trị hiện đại như chi phí Kaizen(thuộc nhóm kỹ thuật quản trị chi phí chiến lược), phân tích khả năng sinh lời khách hàng(thuộc nhóm kỹ thuật quản trị khách hàng), quản trị chuỗi cung ứng, phân tích hiệu quả nhà cung cấp hay quản trị hàng tồn kho kịp thời(thuộc nhóm kỹ thuật quản trị nhà cung cấp) Thẻ Bảng điểm(thuộc nhóm kỹ thuật ra quyết định chiến lược, kiểm soát và đánh giá thành quả) (Đoàn Ngọc Quế và Trịnh Hiệp Thiện 2014).

\section{KẾT LUẬn}

Việc triển khai vận dụng các kỹ thuật KTQT luôn là một biện pháp hữu hiệu để gia tăng tính hiệu quả kinh doanh của bất kỳ $\mathrm{DN}$ nào. Tuy nhiên việc xem xét kỹ mức độ tương thích của quy mô $\mathrm{DN}$ mình với các mô hình KTQT (đã được trình bày rất nhiều và chi tiết ở các nghiên cứu trước) để từ đó lựa chọn ra giải pháp tối ưu sẽ giúp DN cải thiện được hiệu quả kinh doanh, vượt qua được tâm lý e ngại tốn kém chi phí khi vận dụng triển khai mô hình KTQT tại DN mình. Khi lựa chọn mô hình KTQT phù hợp cho bản thân $\mathrm{DN}$ mình, các nhà quản trị nên chú trọng thêm về triển vọng phát triển của $\mathrm{DN}$ trong cả ngắn hạn và dài hạn. Điều này sẽ làm cho $\mathrm{DN}$ chủ động hơn khi chuyển đổi từ mô hình từ $\mathrm{DN}$ siêu nhỏ, $\mathrm{DN}$ nhỏ sang $\mathrm{DN}$ vừa hoặc $\mathrm{DN}$ lớn trong tương lai, vì rõ ràng mô hình KTQT sẽ phải thay đổi để phù hợp với quy mô của DN.

\section{TÀI LIỆU THAM KHẢO}

[1] Đoàn Ngọc Phi Anh (2012), "Nghiên cứu nhân tố ảnh hưởng đến việc vận dụng kế toán quản trị chiến lược trong các doanh nghiệp Việt Nam", Phát triển kinh tế, (264).

[2] Bộ Tài chính, Thông tu số 53/2006/TT-BTC ngày 12 tháng 06 năm 2006 về việc Hướng dẫn áp dụng kế toán quản trị trong doanh nghiệp.

[3] Chính Phủ, Quyết định số 1231/QD-TTg ngày 070/9/2012 về Kế hoạch phát triển DNNVV giai đoạn 2011 2015.

[4] Quốc hội, Luật kế toán số 03/2003/QH11 ngày 17 tháng 06 năm 2003 được tra cứu vào ngày 09 tháng 11 năm 2014 tại http://www.moj.gov.vn/vbpq/Lists/

[5] Phạm Văn Dược (1997), "Phương hướng xây dụng nội dung và tổ chức vận dụng kế toán quản trị vào các doanh nghiệp Việt Nam”, Luận án tiến sĩ. 
[6] Trần Anh Hoa (2003), “Xác lập nội dung và vận dụng kế toán quản trị vào các doanh nghiệp Việt Nam ”, Luận án tiến sĩ.

[7] Đinh Phi Hổ (2011), "Phương pháp nghiên cưu định lương và nhũng nghiên cưu thực tiễn trong kinh tế phát triển - Nông nghiệp”, NXB Phương Đông.

[8] Đoàn Ngọc Quế và Trịnh Hiệp Thiện (2014), Kế toán quản trị chiến lược trong môi trường kinh doanh hiện đại, “Kế toán quản trị trong môi trương kinh doanh hiện đại”, Kỷ yếu hội thảo khoa học, Trường Đại học Kinh Tế TPHCM

[9] Phạm Ngọc Toàn (2010), “Xây dụng nội dung và tổ chức kế toán quản trị cho các doanh nghiệp nhỏ và vùa ở Việt Nam”, Luận án tiến sĩ.

[10] Abdel-Kader, M. and Luther, R. (2006). Management accounting practices in the British food and drinks industry. British Food Journal, vol. 108, no.5, pp. 336-357.

[11] Alper Erserim (2012). The impact of organization culture, firm's characteristics and external environment of firms on management accounting practices: A UK-based empirical analysis: an empirical research on industrial firm in Turkey. Procedia - Social and behavioral Sciences, vol. 62, pp.372-376.

[12] Anthony A. Atkinson, Thorne and Hilton. Management accounting: information creating and managing value, $5^{\text {th }}$ edition, Mc Graw Hill.

[13] CIMA (2005). Management Accounting Official Terminology.

[14] Deros, B.M, Yusof, S.M. and Salled, A.M. (2006). A benchmarking implementation framework for automotive manufacturing SMEs. Benchmarking International Journal, vol. 13, no. 4, pp. 396-43.

[15] IFAC. (1998). International Management Accounting Practice Statement: Management Accounting Concepts. New York.

[16] Langfield-Smith, Thorne Hellen, Hilton Ronald W., Management Accounting: Information for creating and managing value, $5^{\text {th }}$ ed, McGraw-Hill Irwin, 2009.

[17] Marriott, N. and Marriott, P., 2000. Professional accountants and the development of a management accounting service for the small firm: barriers and possibilities. Management Accounting Research, Vol.11, pp. 475-492.

[18] Tuan Zainun Tuan Mat (2010) Management accounting and organizational change: impact of alignment of management accounting system, structure and strategy on performance.

[19] Valančienè, L. and Gimžauskienė, E. (2007). Changing Role of Management Accounting: Lithuanian Experience Case Studies. ISSN 1392-2785, Engineering Economics, no. 5 (55).

Ngày nhận bài: 05/09/2017

Ngày chấp nhận đăng: 25/10/2017 